\title{
Computation of the different topological indices of nanostructures
}

\author{
Najmeh Soleimani, Mohammad Javad Nikmehr* and Hamid Agha Tavallaee \\ Department of Mathematics, Karaj Branch, Islamic Azad University, Karaj, Iran.
}

Revised: 23 September 2014; Accepted: 17 October 2014

\begin{abstract}
In this research study, several topological indices have been investigated for linear [n]-Tetracene, $\mathrm{V}$ - Tetracenic nanotube, H-Tetracenic nanotube and Tetracenic nanotori. The calculated indices are first, second, third and modified second Zagreb indices. In addition, the first and second Zagreb coindices of these nanostructures were calculated. The explicit formulae for connectivity indices of various families of Tetracenic nanotubes and nanotori are presented in this manuscript. These formulae correlate the chemical structure of nanostructures to the information about their physical features.
\end{abstract}

Keywords: Connectivity indices, molecular graph, vertexdegree, Zagreb indices.

\section{INTRODUCTION}

A graph is a collection of points and lines connecting a subset of them. The points and lines of a graph are also called the vertices and edges of the graph, respectively. A simple graph is an unweighted, undirected graph without loops or multiple edges. All of the graphs in this paper are simple. A molecular graph is a simple graph such that its vertices correspond to the atoms and the edges to the bonds (hydrogen atoms are often omitted). In the past years, nanostructures involving carbon have been the focus of intense research, which is driven to a large extent by the quest for new materials with specific applications. A topological index is a numeric quantity of a molecule that is mathematically derived in an unambiguous way from the structural graph of a molecule. In theoretical chemistry, topological indices are used for modelling physical, pharmacological, biological and other properties of chemical compounds. Some exact formulae have been computed for topological indices of nanostructures and some graphs have been plotted. (Eliasi \& Taeri, 2007; Heydari \& Taeri, 2007; Mahmiani et al., 2008; Nikmehr et al., 2014). The use of topological indices as structural descriptors is important in proper and optimal nanostructure design.

The main goal of this paper is to compute some topological indices and polynomials for a family of linear [n]-Tetracene, lattice of V-Tetracenic nanotube, $\mathrm{H}-\mathrm{Tetracenic}$ nanotube and Tetracenic nanotori.

\section{METHODOLOGY}

This section presents some notations as well as preliminary notions, which will be needed for the rest of the paper. A graph $G$ consists of a set of vertices $V(G)$ and a set of edges $E(G)$. The vertices in $G$ are connected by an edge if there exists an edge uv $\in \mathrm{E}(\mathrm{G})$ connecting the vertices $u$ and $v$ in $G$ such that $u, v \in V(G)$. The complement of $\mathrm{G}$, denoted by $\overline{\mathrm{G}}$, is a simple graph on the same set of vertices $V(G)$ in which two vertices $u$ and $v$ are adjacent, i.e., connected by an edge uv, if and only if they are not adjacent in $\mathrm{G}$. Hence, $u v \in \mathrm{E}(\overline{\mathrm{G}}) \Leftrightarrow \mathrm{uv} \notin \mathrm{E}(\mathrm{G})$. The degree $d_{u}$ of a vertex $u \in V(G)$ is the number of vertices of $G$ adjacent to $u$. There are several topological indices already defined.

\section{Zagreb indices and coindices}

One of the oldest graph invariants is the well-known Zagreb indices first introduced by Gutman and Trinajstic (1972) where they have examined the dependence of total $\pi$-electron energy on molecular structure and elaborated (Gutman et al., 1975). For a (molecular) graph G, the first Zagreb index is equal to the sum of the squares of the degrees of the vertices, and the second Zagreb index is equal to the sum of the products of the degrees of pairs of adjacent vertices. In fact, they are defined as: 
$M_{1}(G)=\sum_{u v \in E(G)}\left(d_{u}+d_{v}\right)$

$$
M_{2}(G)=\sum_{u v \in E(G)}\left(d_{u} \times d_{v}\right),
$$

respectively.

The first and second Zagreb polynomials of a graph G are defined as:

$$
\begin{aligned}
& M_{1}(G, x)=\sum_{u v \in E(G)} x^{\left(d_{u}+d_{v}\right)}, \\
& M_{2}(G, x)=\sum_{u v \in E(G)} x^{\left(d_{u} \times d_{v}\right)} .
\end{aligned}
$$

More studies about polynomials in graph theory have been carried out by Ashrafi et al. (2007), FathTabar (2009), Diudea (2010), Mohamadinezhad-Rashti and Yousefi-Azari (2010) and Fath-Tabar and Ashrafi (2011).

A recently proposed variant of the second Zagreb index, which is defined as (Nikolić et al., 2003):

$$
M_{2}^{*}(G)=\sum_{u v \in E(G)} \frac{1}{d_{u} \times d_{v}},
$$

is known under the name modified second Zagreb index.

The third Zagreb index was first introduced by Fath-Tabar (2011). This index is defined as follows:

$$
M_{3}(G)=\sum_{u v \in E(G)}\left|d_{u}-d_{v}\right| \cdot
$$

The first and second Zagreb coindices were first introduced by Ashrafi et al. (2010). They are defined as follows:

$$
\begin{aligned}
& \overline{M_{1}}(G)=\sum_{u v \notin E(G)}\left(d_{u}+d_{v}\right), \\
& \overline{M_{2}}(G)=\sum_{u v \notin E(G)}\left(d_{u} \times d_{v}\right) .
\end{aligned}
$$

It should be noted that Zagreb coindices of $G$ are not Zagreb indices of $\overline{\mathrm{G}}$; the defining sums run over $E(\overline{\mathrm{G}})$, but the degrees are with respect to $\mathrm{G}$.

\section{Some connectivity indices}

Among topological descriptors, connectivity indices are very important and they have a prominent role in chemistry. The product-connectivity index, also called Randić index of a graph $\mathrm{G}$ is defined such as:

$$
\chi(G)=\sum_{u v \in E(G)} \frac{1}{\sqrt{d_{u} d_{v}}},
$$

This topological index was first proposed by Randić (1975). The concept of atom-bond connectivity index was introduced in the chemical graph theory by Estrada et al. (1998). The atom-bond connectivity index of a graph $\mathrm{G}$ is defined as follows:

$$
A B C(G)=\sum_{u v \in E(G)} \sqrt{\frac{d_{u}+d_{v}-2}{d_{u} d_{v}} .}
$$

Zhou and Trinajstić (2009) proposed another connectivity index, named the sum-connectivity index. This index is defined as follows:

$$
X(G)=\sum_{u v \in E(G)} \frac{1}{\sqrt{d_{u}+d_{v}}} .
$$

The geometric-arithmetic index is another topological index based on degrees of vertices defined by Vukičević and Furtula (2009):

$G A(G)=\sum_{u v \in E(G)} \frac{2 \sqrt{d_{u} d_{v}}}{d_{u}+d_{v}}$.

\section{RESULTS AND DISCUSSION}

The use of topological and connectivity indices as structural descriptors is important in proper and optimal nanostructure design. The combinatorial design approach appears to be a useful platform for numerical experimentation in the design of nanostructures. The acenes or polyacenes are a class of organic compounds and polycyclic aromatic hydrocarbons made up of linearly fused benzene rings. The larger representatives have potential interest in optoelectronic applications and are actively researched in Chemistry and Electrical Engineering. Tetracene, also called naphthacene, is a polycyclic aromatic hydrocarbon. It has the appearance of a pale orange powder. Tetracene is the four-ringed member of the series of acenes. Figure 1 shows the linear $[\mathrm{n}]$-Tetracene. 


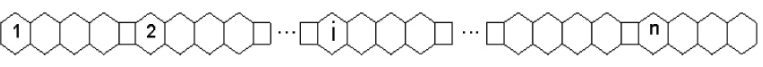

Figure 1: The molecular graph of a linear [n]-Tetracene.

Before proceeding to the main results, the next section will prove two simple lemmas, which will be useful later.

Lemma 3.1 It holds that:

Table 1: Computing the number of vertices and edges for a linear [n]Tetracene

\begin{tabular}{lccccc}
\hline Nanostructure & $|\mathrm{V}|$ & $|\mathrm{E}|$ & $\left|\mathrm{E}_{1}\right|$ & $\left|\mathrm{E}_{2}\right|$ & $\left|\mathrm{E}_{3}\right|$ \\
\hline $\mathrm{T}$ & $18 \mathrm{n}$ & $23 \mathrm{n}-2$ & 6 & $16 \mathrm{n}-4$ & $7 \mathrm{n}-4$ \\
\hline
\end{tabular}

Proof. Obviously, for $\mathrm{n}=1$ (Figure 2) $|\mathrm{V}|=18$ and $|\mathrm{E}|=$ 21. Also, there exist 3 types of edges, namely $\left[E_{1}\right]=u v$, $\left[\mathrm{E}_{2}\right]=\mathrm{xy}$ and $\left[\mathrm{E}_{3}\right]=\mathrm{ab}$. On the other hand $\mathrm{d}_{\mathrm{u}}=\mathrm{d}_{\mathrm{v}}=$ $2, \mathrm{~d}_{\mathrm{a}}=\mathrm{d}_{\mathrm{b}}=3$ and $\mathrm{d}_{\mathrm{x}}=3, \mathrm{~d}_{\mathrm{y}}=2$. By enumerating these edges there are 6,12 and 3 edges of types 1,2 and 3, respectively.

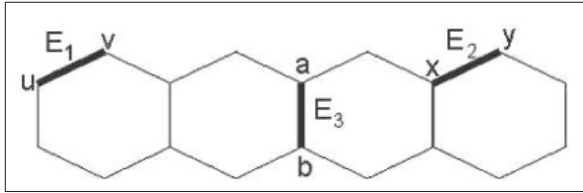

Figure 2: Basic structure of a Tetracene

Now, it is easy to see that $\mathrm{T}=\mathrm{T}[\mathrm{n}]$ has $18 \mathrm{n}$ vertices and $23 n-2$ edges, and similar to the above argument we can see that the edge set of the graph can be divided to three partitions, e.g. $\mathrm{E}_{1}(\mathrm{~T}), \mathrm{E}_{2}(\mathrm{~T})$ and $\mathrm{E}_{3}(\mathrm{~T})$. There are three types of edges, e.g. edges with endpoints $2\left[\mathrm{E}_{1}\right]$, edges with endpoints $2,3\left[\mathrm{E}_{2}\right]$ and edges with endpoints $3\left[\mathrm{E}_{3}\right]$. By using an algebraic method we obtain $\left|\mathrm{E}_{1}\right|=6$, $\left|E_{2}\right|=16 n-4$ and $\left|E_{3}\right|=7 n-4$.

Theorem 3.1 Let $\mathrm{T}$ be linear [n]-Tetracene, we have

i. $M_{1}(T, x)=(7 n-4) x^{6}+(16 n-4) x^{5}+6 x^{4}$.

ii. $M_{2}(T, x)=(7 n-4) x^{9}+(16 n-4) x^{6}+6 x^{4}$.

Proof. By definitions of the first and second Zagreb polynomials and partition of edges described in Table 1 of Lemma 3.1, we can see that:

i. $M_{1}(T, x)=\sum_{u v \in E(T)} x^{\left(d_{u}+d_{v}\right)}=\sum_{u v \in\left[E_{1}\right]} x^{4}+\sum_{u v \in\left[E_{2}\right]} x^{5}+\sum_{u v \in\left[E_{3}\right]} x^{6}=6 x^{4}+(16 n-4) x^{5}+(7 n-4) x^{6}$.

ii. $\mathrm{M}_{2}(\mathrm{~T}, \mathrm{x})=\sum_{\mathrm{uv} \in \mathrm{E}(\mathrm{T})} \mathrm{x}^{\left(\mathrm{d}_{\mathrm{u}} \times \mathrm{d}_{\mathrm{v}}\right)}=\sum_{\mathrm{uv} \in\left[\mathrm{E}_{1}\right]} \mathrm{x}^{4}+\sum_{\mathrm{uv} \in\left[\mathrm{E}_{2}\right]} \mathrm{x}^{6}+\sum_{\mathrm{uv} \in\left[\mathrm{E}_{3}\right]} \mathrm{x}^{9}=6 \mathrm{x}^{4}+(16 n-4) \mathrm{x}^{6}+(7 n-4) \mathrm{x}^{9}$.

Next we calculate the first and second Zagreb indices for a linear [n]-Tetracene.

Theorem 3.2 Let $\mathrm{T}$ be a linear [n]-Tetracene, we have

i. $M_{1}(T)=122 n-20$.

ii. $M_{2}(T)=159 n-36$.

Proof. We know the first and second Zagreb indices will be the first derivative of $M_{1}(T, x)$ and $M_{2}(T, x)$ evaluated at $\mathrm{x}=1$, respectively. Thus,

i. $\mathrm{M}_{1}(\mathrm{~T})=\left.\frac{\partial \mathrm{M}_{1}(\mathrm{~T}, \mathrm{x})}{\partial \mathrm{x}}\right|_{\mathrm{x}=1}=6 \times(7 \mathrm{n}-4)+5 \times(16 \mathrm{n}-4)+4 \times(6)=122 \mathrm{n}-20$.

ii. $\mathrm{M}_{2}(T)=\left.\frac{\partial \mathrm{M}_{2}(T, \mathrm{x})}{\partial \mathrm{x}}\right|_{\mathrm{x}=1}=9 \times(7 \mathrm{n}-4)+6 \times(16 \mathrm{n}-4)+4 \times(6)=159 \mathrm{n}-36$. 
Given the number of edges linear [n]-Tetracene and definitions listed with algebraic operations, we can prove the following theorem:

Theorem 3.3 Consider the graph $\mathrm{T}$ of a linear [n]-Tetracene. Then

$$
\begin{aligned}
& \text { i. } M_{2}^{*}(T)=\sum_{\mathrm{uv} \in \mathrm{E}(\mathrm{T})} \frac{1}{\mathrm{~d}_{\mathrm{u}} \times \mathrm{d}_{\mathrm{v}}}=\sum_{\mathrm{uv} \in\left[\mathrm{E}_{1}\right]} \frac{1}{4}+\sum_{\mathrm{uv} \in\left[\mathrm{E}_{2}\right]} \frac{1}{6}+\sum_{\mathrm{uv} \in\left[\mathrm{E}_{3}\right]} \frac{1}{9}=\frac{1}{4} \times 6+\frac{1}{6} \times(16 \mathrm{n}-4)+\frac{1}{9} \times(7 \mathrm{n}-4)=\frac{31}{9} \mathrm{n}+\frac{7}{18} . \\
& \text { ii. } \mathrm{M}_{3}(\mathrm{~T})=\sum_{\mathrm{uv} \in \mathrm{E}(\mathrm{T})}\left|\mathrm{d}_{\mathrm{u}}-\mathrm{d}_{\mathrm{v}}\right|=\sum_{\mathrm{uv} \in\left[\mathrm{E}_{2}\right]}|2-3|=16 \mathrm{n}-4 \text {. } \\
& \text { iii. } \chi(T)=\sum_{\mathrm{uv} \in E(T)} \frac{1}{\sqrt{\mathrm{du}_{\mathrm{u}} \mathrm{d}_{\mathrm{v}}}}=\sum_{\mathrm{uv} \in\left[\mathrm{E}_{1}\right]} \frac{1}{\sqrt{4}}+\sum_{\mathrm{uv} \in\left[\mathrm{E}_{2}\right]} \frac{1}{\sqrt{6}}+\sum_{\mathrm{uv} \in\left[\mathrm{E}_{3}\right]} \frac{1}{\sqrt{9}}=\frac{1}{\sqrt{4}} \times 6+\frac{1}{\sqrt{6}} \times(16 \mathrm{n}-4)+\frac{1}{\sqrt{9}} \times(7 \mathrm{n}-4)=\left(\frac{8 \sqrt{6}+7}{3}\right) \mathrm{n}+\left(\frac{5-2 \sqrt{6}}{3}\right) \\
& \text { iv. } X(T)=\sum_{\mathrm{uv} \in \mathrm{E}(\mathrm{T})} \frac{1}{\sqrt{\mathrm{d}_{\mathrm{u}}+\mathrm{d}_{\mathrm{v}}}}=\sum_{\mathrm{uv} \in\left[\mathrm{E}_{1}\right]} \frac{1}{\sqrt{4}}+\sum_{\mathrm{uv} \in\left[\mathrm{E}_{2}\right]} \frac{1}{\sqrt{5}}+\sum_{\mathrm{uv} \in\left[\mathrm{E}_{3}\right]} \frac{1}{\sqrt{6}}=\frac{1}{\sqrt{4}} \times 6+\frac{1}{\sqrt{5}} \times(16 \mathrm{n}-4)+\frac{1}{\sqrt{6}} \times(7 \mathrm{n}-4)=\left(\frac{16 \sqrt{5}}{5}+\frac{7 \sqrt{6}}{6}\right) \mathrm{n}+\left(3-\frac{4 \sqrt{5}}{5}-\frac{4 \sqrt{6}}{6}\right) \text {. } \\
& \text { v. } G A(T)=\sum_{\mathrm{uv} \in E(T)} \frac{2 \sqrt{\mathrm{du}_{\mathrm{u}} \mathrm{d}_{\mathrm{v}}}}{\mathrm{d}_{\mathrm{u}}+\mathrm{d}_{\mathrm{v}}}=\sum_{\mathrm{uv} \in\left[\mathrm{E}_{1}\right]} \frac{2 \sqrt{4}}{4}+\sum_{\mathrm{uv} \in\left[\mathrm{E}_{2}\right]} \frac{2 \sqrt{6}}{5}+\sum_{\mathrm{uv} \in\left[\mathrm{E}_{3}\right]} \frac{2 \sqrt{9}}{6}=\frac{2 \sqrt{4}}{4} \times 6+\frac{2 \sqrt{6}}{5} \times(16 \mathrm{n}-4)+\frac{2 \sqrt{9}}{6} \times(7 \mathrm{n}-4)=\left(7+\frac{32 \sqrt{6}}{5}\right) \mathrm{n}+\left(2-\frac{8 \sqrt{6}}{5}\right) \text {. } \\
& \text { vi. } A B C(T)=\sum_{u v E E(T)} \sqrt{\frac{d_{\mathrm{d}_{u}+\mathrm{d}_{\mathrm{v}}-2}}{\mathrm{~d}_{\mathrm{u}} \mathrm{d}_{\mathrm{v}}}}=\sum_{\mathrm{uv} \in\left[\mathrm{E}_{1}\right]} \sqrt{\frac{2}{4}}+\sum_{\mathrm{uv} \in\left[\mathrm{E}_{2}\right]} \sqrt{\frac{3}{6}}+\sum_{\mathrm{uv} \in\left[\mathrm{E}_{3}\right]} \sqrt{\frac{4}{9}}=\sqrt{\frac{2}{4}} \times 6+\sqrt{\frac{3}{6}} \times(16 n-4)+\sqrt{\frac{4}{9}} \times(7 n-4)=\left(\frac{14+24 \sqrt{2}}{3}\right) \mathrm{n}+\left(\frac{3 \sqrt{2}-8}{3}\right) \text {. }
\end{aligned}
$$

Lemma 3.2 (Ashrafi et al., 2010) Let G be a simple graph with $n$ vertices. Then

i. $\overline{M_{1}}(G)=2|E(G)|(n-1)-M_{1}(G)$.

ii. $\overline{\mathrm{M}_{2}}(\mathrm{G})=2|\mathrm{E}(\mathrm{G})|^{2}-\mathrm{M}_{2}(\mathrm{G})-1 / 2 \mathrm{M}_{1}(\mathrm{G})$.

Proof. By applying Lemma 3.1 and Lemma 3.2, we are done.

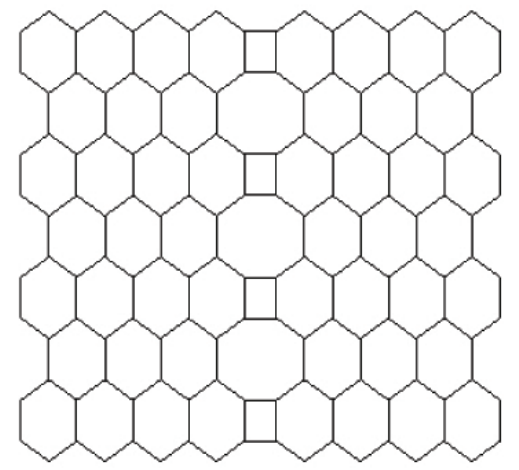

Figure 3: The 2-D graph lattice of $F=F[p, q]$ with $p=2$ and $q=4$

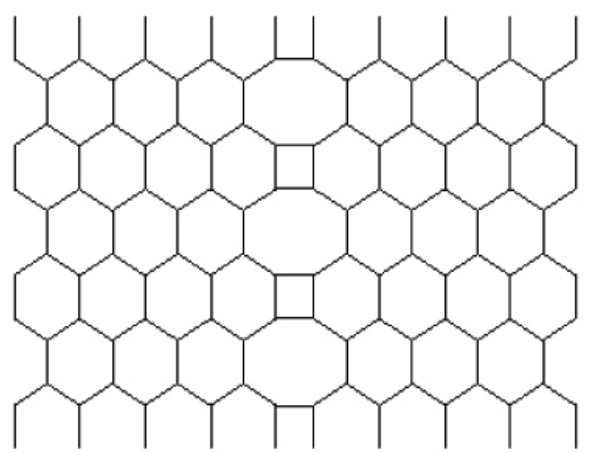

Figure 5: The 2-D graph lattice of $K=K[p, q]$ with $p=2$ and $q=3$
Figure 4: The 2-D graph lattice of $\mathrm{G}=\mathrm{G}[\mathrm{p}, \mathrm{q}]$ with $\mathrm{p}=2$ and $\mathrm{q}=4$

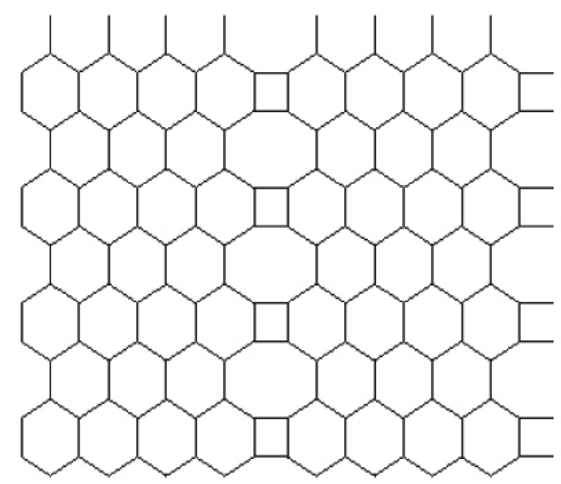

Figure 6: The 2-D graph lattice of $L=L[p, q]$ with $p=2$ and $q=4$
Theorem 3.4 The first and second Zagreb coindices of a linear [n]Tetracene are computed as:

\begin{tabular}{lll}
\hline Nanostructure & $\overline{M_{1}}$ & $\overline{M_{2}}$ \\
\hline$T$ & $828 n^{2}-240 n+24$ & $1058 n^{2}-404 n+54$
\end{tabular}

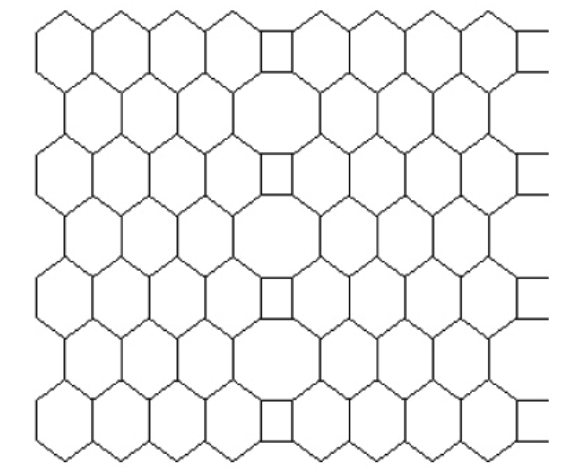

Journal of the National Science Foundation of Sri Lanka 43(2) 
The following Lemma is crucial for our main results.

Lemma 3.3 It holds that:

Table 2: Computing the number of vertices and edges

\begin{tabular}{llllll}
\hline Nanostructure & $|\mathrm{V}|$ & $|\mathrm{E}|$ & $\left|\mathrm{E}_{1}\right|$ & $\left|\mathrm{E}_{2}\right|$ & $\left|\mathrm{E}_{3}\right|$ \\
\hline $\mathrm{F}$ & $18 \mathrm{pq}$ & $27 \mathrm{pq}-2 \mathrm{q}-4 \mathrm{p}$ & $2 \mathrm{q}+4$ & $16 \mathrm{p}+4 \mathrm{q}-8$ & $27 \mathrm{pq}-20 \mathrm{p}-8 \mathrm{q}+4$ \\
$\mathrm{G}$ & $18 \mathrm{pq}$ & $27 \mathrm{pq}-4 \mathrm{p}$ & 0 & $16 \mathrm{p}$ & $27 \mathrm{pq}-20 \mathrm{p}$ \\
$\mathrm{K}$ & $18 \mathrm{pq}$ & $27 \mathrm{pq}-2 \mathrm{q}$ & $2 \mathrm{q}$ & $4 \mathrm{q}$ & $27 \mathrm{pq}-8 \mathrm{q}$ \\
$\mathrm{L}$ & $18 \mathrm{pq}$ & $27 \mathrm{pq}$ & 0 & 0 & $27 \mathrm{pq}$ \\
\hline
\end{tabular}

Proof. We apply a similar reasoning as in the proof of Lemma 3.1 to calculate the quantities of $|\mathrm{V}|,\left|\mathrm{E}_{1}\right|,\left|\mathrm{E}_{2}\right|$ and $\left|\mathrm{E}_{3}\right|$ of the nanostructures $\mathrm{F}, \mathrm{G}, \mathrm{K}$ and $\mathrm{L}$.
By this table and a case-by-case investigation on the molecular graphs as shown in Figures 3, 4, 5 and 6 led to the following observations:

Theorem 3.5 The first and second Zagreb polynomials of nanostructures are computed as:

\begin{tabular}{ll}
\hline Nanostructure & The first Zagreb polynomial \\
\hline F & $(27 p q-20 p-8 q+4) x^{6}+(16 p+4 q-8) x^{5}+(2 q+4) x^{4}$ \\
G & $(27 p q-20 p) x^{6}+16 p x^{5}$ \\
K & $(27 p q-8 q) x^{6}+4 q x^{5}+2 q x^{4}$ \\
L & $27 p q x^{6}$ \\
\hline & \\
\hline Nanostructure & The second Zagreb polynomial \\
\hline F & $(27 p q-20 p-8 q+4) x^{9}+(16 p+4 q-8) x^{6}+(2 q+4) x^{4}$ \\
G & $(27 p q-20 p) x^{9}+16 p x^{6}$ \\
K & $(27 p q-8 q) x^{9}+4 q x^{6}+2 q x^{4}$ \\
L & $27 p q x^{9}$ \\
\hline
\end{tabular}

Proof. The proof follows from Theorem 3.1.

Theorem 3.6 The first, second, modified second and third Zagreb indices of nanostructures are computed as:

\begin{tabular}{lllll}
\hline Nanostructure & $\mathrm{M}_{1}$ & $\mathrm{M}_{2}$ & $\mathrm{M}_{2}^{*}$ & $\mathrm{M}_{3}$ \\
\hline $\mathrm{F}$ & $162 \mathrm{pq}-40 \mathrm{p}-20 \mathrm{q}$ & $243 \mathrm{pq}-84 \mathrm{p}-40 \mathrm{q}+4$ & $3 \mathrm{pq}+\frac{4}{9} \mathrm{p}+\frac{5}{18} \mathrm{q}+\frac{1}{9}$ & $16 \mathrm{p}+4 \mathrm{q}-8$ \\
$\mathrm{G}$ & $162 \mathrm{pq}-40 \mathrm{p}$ & $243 \mathrm{pq}-84 \mathrm{p}$ & $3 \mathrm{pq}+\frac{4}{9} \mathrm{p}$ & $16 \mathrm{p}$ \\
$\mathrm{K}$ & $162 \mathrm{pq}-20 \mathrm{q}$ & $243 \mathrm{pq}-40 \mathrm{q}$ & $3 \mathrm{pq}+\frac{5}{18} \mathrm{q}$ & $4 \mathrm{q}$ \\
$\mathrm{L}$ & $162 \mathrm{pq}$ & $243 \mathrm{pq}$ & $3 p q$ & 0 \\
\hline
\end{tabular}

Proof. The proof is clear, by using Lemma 3.3 and proof of Theorem 3.3.

Example 3.1 Let $\mathrm{F}=\mathrm{F}[3,10]$ be a lattice with 540 atoms and 778 chemical bonds. Then one can see that $\mathrm{M}_{1}(\mathrm{~F})=4540$, $\mathrm{M}_{2}(\mathrm{~F})=6642, \mathrm{M}_{2}^{*}(\mathrm{~F})=94.2222$ and $\mathrm{M}_{3}(\mathrm{~F})=80$. 
Theorem 3.7 The first and second Zagreb coindices of nanostructures are computed as:

\begin{tabular}{|c|c|c|c|}
\hline & \multicolumn{2}{|c|}{ Nanostructure } & $\overline{\mathrm{M}_{1}}$ \\
\hline & $\mathrm{F}$ & & $972 p^{2} q^{2}-144 p^{2} q-72 p q^{2}-216 p q+48 p+24 q$ \\
\hline & G & & $972 p^{2} q^{2}-144 p^{2} q-216 p q+48 p$ \\
\hline & $\mathrm{K}$ & & $972 p^{2} q^{2}-72 p q^{2}-216 p q+24 q$ \\
\hline & $\mathrm{L}$ & & $972 p^{2} q^{2}-216 p q$ \\
\hline \multicolumn{2}{|c|}{ Nanostructure } & \multicolumn{2}{|l|}{$\overline{\mathrm{M}_{2}}$} \\
\hline $\mathrm{F}$ & \multicolumn{3}{|c|}{$1458 p^{2} q^{2}-432 p^{2} q-216 p q^{2}+32 p^{2}+8 q^{2}-292 p q+104 p+50 q-4$} \\
\hline G & \multicolumn{3}{|c|}{$1458 p^{2} q^{2}-432 p^{2} q+32 p^{2}-324 p q+104 p$} \\
\hline K & \multicolumn{3}{|c|}{$1458 p^{2} q^{2}-216 p q^{2}+8 q^{2}-324 p q+50 q$} \\
\hline $\mathrm{L}$ & \multicolumn{3}{|c|}{$1458 p^{2} q^{2}-324 p q$} \\
\hline
\end{tabular}

Proof. We have just applied the Lemma 3.2, Lemma 3.3 and using the Theorem 3.6.

Example 3.2 Let $\mathrm{L}=\mathrm{L}[2,4]$ be a nanotube with 144 atoms and 216 chemical bonds. Then one can see that $\overline{\mathrm{M}_{1}}(\mathrm{~L})=60480$ and $\overline{\mathrm{M}_{2}}(\mathrm{~L})=90720$.

Finally, we calculate the Randić index, Sum-connectivity index, geometric-arithmetic index and atom-bond connectivity index of nanostructures by using an algebraic method. In general we have the following theorem without proof:
Example 3.3 Let $\mathrm{F}=\mathrm{F}[2,4]$ be a nanotube with 144 atoms and 200 chemical bonds. Then one can see that $\chi(\mathrm{F})=71.6632$ and $X(\mathrm{~F})=84.3093$.

Example 3.4 Let $G=G[2,4]$ be a nanotube with 144 atoms and 208 chemical bonds. Then one can see that $\mathrm{ABC}(\mathrm{G})=139.9607$.

Example 3.5 Let $\mathrm{K}=\mathrm{K}[2,3]$ be a nanotube with 108 atoms and 156 chemical bonds. Then one can see that $\mathrm{GA}(\mathrm{K})=155.7575$.

Theorem 3.8 The connectivity indices of nanostructures are computed as:

\begin{tabular}{ll}
\hline Nanostructure & $x$ \\
\hline F & $9 p q+\left(\frac{8 \sqrt{6}-20}{3}\right) p+\left(\frac{2 \sqrt{6}-5}{3}\right) q+\left(\frac{10-4 \sqrt{6}}{3}\right)$ \\
G & $9 p q+\left(\frac{8 \sqrt{6}-20}{3}\right) p$ \\
K & $9 p q+\left(\frac{2 \sqrt{6}-5}{3}\right) q$ \\
L & $9 p q$ \\
\hline
\end{tabular}

\begin{tabular}{ll}
\hline Nanostructure & $\mathbf{X}$ \\
\hline $\mathrm{F}$ & $\frac{9 \sqrt{6}}{2} \mathrm{pq}+\left(\frac{48 \sqrt{5}-50 \sqrt{6}}{15}\right) \mathrm{p}+\left(\frac{15+12 \sqrt{5}-20 \sqrt{6}}{15}\right) \mathrm{q}+\left(\frac{60-48 \sqrt{5}+20 \sqrt{6}}{30}\right)$ \\
$\mathrm{G}$ & $\frac{9 \sqrt{6}}{2} \mathrm{pq}+\left(\frac{48 \sqrt{5}-50 \sqrt{6}}{15}\right) \mathrm{p}$ \\
$\mathrm{K}$ & $\frac{9 \sqrt{6}}{2} \mathrm{pq}+\left(\frac{15+12 \sqrt{5}-20 \sqrt{6}}{15}\right) \mathrm{q}$ \\
$\mathrm{L}$ & $\frac{9 \sqrt{6}}{2} \mathrm{pq}$ \\
\hline
\end{tabular}


Theorem 3.9 The atom-bond connectivity index of nanostructures are computed as:

\begin{tabular}{ll}
\hline Nanostructure & ABC \\
\hline F & $18 p q+\left(\frac{24 \sqrt{2}-40}{3}\right) p+\left(\frac{9 \sqrt{2}-16}{3}\right) q+\left(\frac{8-6 \sqrt{2}}{3}\right)$ \\
G & $18 p q+\left(\frac{24 \sqrt{2}-40}{3}\right) p$ \\
K & $18 p q+\left(\frac{9 \sqrt{2}-16}{3}\right) \mathrm{q}$ \\
L & $18 p q$ \\
\hline
\end{tabular}

Theorem 3.10 The geometric-arithmetic index of nanostructures are computed as:

\begin{tabular}{ll}
\hline Nanostructure & GA \\
\hline F & $27 p q+\left(\frac{32 \sqrt{62}-100}{5}\right) p+\left(\frac{8 \sqrt{6}-30}{5}\right) q+\left(\frac{40-16 \sqrt{6}}{5}\right)$ \\
G & $27 p q+\left(\frac{32 \sqrt{62}-100}{5}\right) p$ \\
K & $27 p q+\left(\frac{8 \sqrt{6}-30}{5}\right) q$ \\
L & $27 p q$ \\
\hline
\end{tabular}

\section{CONCLUSION}

Chemical graph theory is an important tool for studying molecular structures and has an important effect on the development of chemical sciences. The study of topological indices is currently one of the most active research fields in chemical graph theory. We have presented here some theoretical results on the Zagreb and connectivity indices of the linear [n]-Tetracene, V-Tetracenic nanotube, H-Tetracenic nanotube and Tetracenic nanotori. These formulae make it possible to correlate the chemical structure of nanostructures with a large amount of information about their physical features.

\section{Acknowledgement}

The authors would like to thank the anonymous referees for their helpful comments that have improved the presentation of results in this article.

\section{REFERENCES}

1. Ashrafi A.R., Manoochehrian B. \& Yousefi-Azari H. (2007). On Szeged polynomial of a graph. Bulletin of the Iranian Mathematical Society 33: 37 - 46.
2. Ashrafi A.R., Došlić T. \& Hamzeh A. (2010). The Zagreb coindices of graph operations. Discrete Applied Mathematics 158: 1571 - 1578.

DOI: http://dx.doi.org/10.1016/j.dam.2010.05.017

3. Diudea M.V. (2010). Omega polynomial in all R[8] lattices. Iranian Journal of Mathematical Chemistry 1(1): 69 - 77.

4. Eliasi M. \& Taeri B. (2007). Balaban index of zigzag polyhex nanotorus. Journal of Computational and Theoretical Nanoscience 4: 1174 - 1178.

5. Estrada E., Torres L., Rodriguez L. \& Gutman I. (1998). An atom-bond connectivity index: modelling the enthalpy of formation of alkanes. Indian Journal of Chemistry 37(A): $849-855$.

6. Fath-Tabar G.H. (2009). Zagreb polynomial and PI indices of some nano structures. Digest Journal of Nanomaterials and Biostructures 4: $189-191$.

7. Fath-Tabar G.H. \& Ashrafi A.R. (2011). The hyper-Wiener polynomial of graphs. Iranian Journal of Mathematical Sciences and Informatics 6(2): $67-74$.

8. Fath-Tabar G.H. (2011). Old and new zagreb indices of graphs. MATCH. Communications in Mathematical and in Computer Chemistry 65: $79-84$.

9. Gutman I. \& Trinajstić N. (1972). Graph theory and molecular orbitals, total $\pi$-electron energy of alternant hydrocarbons. Chemical Physics Letters 17: 535 - 538.

10. Gutman I., Ru ščić B., Trinajstiċ N. \& Wilcox C.F. (1975). Graph theory and molecular orbitals. XII. acyclic polyenes. The Journal of Chemical Physics 62: 3399 - 3405. DOI: http://dx.doi.org/10.1063/1.430994

11. Heydari A. \& Taeri B. (2007). Wiener and Schultz indices of $\mathrm{TUC}_{4} \mathrm{C}_{8}(\mathrm{~S})$ nanotubes. MATCH. Communications in Mathematical and in Computer Chemistry 57: 665 - 676.

12. Mahmiani A., Iranmanesh A. \& Pakravesh Y. (2008). Szeged index of armchair polyhex nanotube. Ars Combinatoria 89: 309 - 319 .

13. Mohamadinezhad-Rashti H. \& Yousefi-Azari H. (2010). Some new results on the Hosoya polynomial of graph operations. Iranian Journal of Mathematical Chemistry 1(2): $37-43$.

14. Nikmehr M.J., Heidarzadeh L. \& Soleimani N. (2014). Calculating different topological indices of total graph of $\mathrm{Z}_{\mathrm{n}}$. Studia Scientiarum Mathematicarum Hungarica 51(1): $133-140$

DOI: http://dx.doi.org/10.1556/SScMath.51.2014.1.1270

15. Nikolić S., Kovačević G., Miličević A. \& Trinajstić N. (2003). The Zagreb indices 30 years after. Croatica Chemica Acta 76: 113 - 124.

16. Randić M. (1975). On characterization of molecular branching. Journal of the American Chemical Society 97: $6609-6615$.

DOI: http://dx.doi.org/10.1021/ja00856a001

17. Vukičević D. \& Furtula B. (2009). Topological index based on the ratios of geometrical and arithmetical means of end-vertex degrees of edges. Journal of Mathematical Chemistry 46: 1369 - 1376.

DOI: http://dx.doi.org/10.1007/s10910-009-9520-x

18. Zhou B. \& Trinajstić N. (2009). On a novel connectivity index. Journal of Mathematical Chemistry 46: 1252 1270.

DOI: http://dx.doi.org/10.1007/s10910-008-9515-z 